\title{
Renin gene rs 1464816 polymorphism contributes to chronic kidney disease progression in ADPKD
}

\author{
Gnanasambandan Ramanathan ${ }^{1}$, Ramprasad Elumalai ${ }^{2}$ Soundararajan Periyasamy ${ }^{2}$ \\ and Bhaskar V. K. S. Lakkakula ${ }^{1,3^{*}}$
}

\begin{abstract}
Background: Autosomal dominant polycystic kidney disease (ADPKD) is a monogenic disorder and is a common genetic cause of chronic renal failure in children and adults. The enzyme renin plays a key role in the RAAS cascade and an important role in the development of hypertension and progression of renal disease in ADPKD. The present study is aimed to investigate the potential modifier effect of REN gene polymorphisms on the progression of chronic kidney disease (CKD) in ADPKD.

Methods: We analyzed 102 ADPKD patients and 106 healthy controls from the same geographic area. FRET-based KASPar single-nucleotide polymorphism (SNP) genotyping assays for REN gene tag-SNPs (rs2887284, rs2368564, rs1464816, rs7521667, rs10900555, rs6693954, rs6676670 and rs11571078) were performed. Cochran-Armitage trend test was used to assess the potential associations between these polymorphisms and CKD stages. Haplotype frequencies and LD measures were estimated by using the software Haploview. Mantel-Haenszel stratified analysis was used to explore confounding and interaction effects of these polymorphisms.
\end{abstract}

Results: Of the eight tag-SNPs genotyped, the rs 10900555 polymorphism deviated from the Hardy-Weinberg equilibrium in controls. The presence of ADPKD in general was not significantly associated with the REN tag-SNPs included in this study. Linkage disequilibrium analysis yielded three haplotype blocks and the haplotypes of the respective blocks are not statistically different between ADPKD and controls. In multivariate analysis, the rs 1464816 TG genotype showed a significant association with the advancement of CKD in ADPKD (OR=4.80; $95 \% \mathrm{Cl}=1.30-17.82 ; p=0.019)$.

Conclusions: The present study provides evidence that the rs 1464816 polymorphism in REN is associated with CKD progression in ADPKD.

Keywords: REN gene, ADPKD, CKD, tag-SNPs

\section{Background}

Autosomal dominant polycystic kidney disease (ADPKD) is a monogenic disorder and a common genetic cause of chronic renal failure in children and adults. It is characterized by the accumulation of fluid-filled cysts in both kidneys and other organs [1]. According to epidemiological data, ADPKD affects at least 10 million individuals worldwide. Around $10 \%$ of the patients may develop end-stage

\footnotetext{
* Correspondence: bhaskar@scic.co.in

'Department of Biomedical Sciences, Sri Ramachandra University, Chennai, India

${ }^{3}$ Genetic Lab, Department of Biochemistry, Sickle Cell Institute Chhattisgarh, Pt. JNM Medical College, Raipur 492001CG, India

Full list of author information is available at the end of the article
}

renal disease (ESRD) during the fourth and fifth decades of their life and need renal replacement therapy by haemodialysis or transplantation. ADPKD is genetically heterogeneous: mutations in PKD1 account for $85-90 \%$ of cases and mutations in PKD2 and undefined PKD3 account for $10-15 \%$ of cases [2]. A striking feature of ADPKD is its intrafamilial and interfamilial phenotypic variability. The age of onset of renal disease progression in ADPKD has been observed 15 years earlier in patients from PKD1linked families than patients from PKD2-linked families [3]. Further, considerable renal disease variability has been observed among individuals with the same PKD2 mutations. This variability supports the notion that there are 
additional genetic, environmental and stochastic factors that contribute to renal disease progression in ADPKD [4]. The predictive links between severities of divergent phenotypes in ADPKD have not been identified so far [5]. In about $60 \%$ of ADPKD patients, hypertension can be noticed before identifying any decrease in the glomerular filtration rate and relates to progressive kidney enlargement in ADPKD [6]. In both male and female ADPKD patients, a significant reduction in renal disease progression was associated with significantly lower mean arterial pressure and increased use of angiotensin-converting enzyme inhibitors (ACEIs) [7]. The activation of the intrarenal renin-angiotensin-aldosterone system (RAAS) plays a major role in the pathogenesis of hypertension in ADPKD [8]. Thus, the genes involved in the RAAS have an important role in the development of hypertension and progression of renal disease. The enzyme renin plays a key role in the RAAS cascade by cleaving the precursor angiotensinogen to release angiotensin II from angiotensin I. Plasma renin activity was found to be increased in hypertensive ADPKD patients compared to control subjects [9-11]. The gene coding for renin (REN) is located on chromosome $1 \mathrm{q} 32$, spans $12.5 \mathrm{~kb}$ in length and encodes the 406 amino acid precursor of renin that includes a pre- and a prosegment carrying 20 and 46 amino acids, respectively. Mature renin contains 340 amino acids and has a mass of $37 \mathrm{kDa}$ [12]. Studies concerned with REN polymorphisms and essential hypertension revealed inconsistent results $[13,14]$. The present study is aimed at unraveling the potential modifier effect of the REN gene tag-SNP on the progression of chronic kidney disease (CKD) in ADPKD.

\section{Methods}

\section{Subjects}

A total of 102 south Indian patients with ADPKD, $55.88 \%$ of whom are men, were recruited from the Department of Nephrology of Sri Ramachandra University, Chennai, between February 2000 and June 2014. The diagnosis of ADPKD was done based on previously described Ravine ultrasound criteria [15]. From serum creatinine levels of each patient, estimated glomerular filtration rate (eGFR) was calculated using the Modification of Diet in Renal Disease (MDRD) study formula. Further among the ADPKD patients, chronic kidney disease was defined according to the Kidney Disease Outcomes Quality Initiative (KDOQI) criteria for stages of CKD and patients were divided into different stages - early stages (CKD stages 1-3) and advanced stages (CKD stages 4 and 5) by using eGFR [16]. A total 106 healthy unrelated individuals without any kidney related disease $(60.38 \%$ of whom are men) from the same geographic location were included as controls. The study was approved by the Institutional Ethical Committee of Sri Ramachandra University, Chennai, India. After obtaining written informed consent, three $\mathrm{mL}$ peripheral blood sample was obtained from all subjects. Genomic DNA was isolated according to the standard procedure [17].

\section{Genotyping}

REN tag-SNPs (rs2887284, rs2368564, rs1464816, rs7521667, rs10900555, rs6693954, rs6676670 and rs11571078) ascertained from genotyped SNPs in a Gujarati Indians in Houston population (GIH) in phase II of the HapMap Project with a minor allele frequency (MAF) $\geq 0.05$ and linkage disequilibrium patterns with $\mathrm{r}^{2} \geq 0.8$ were used as a cutoff (www.hapmap.org). The KASPar SNP Genotyping Method (KBioscience, Herts., UK) that uses Fluorescent Resonance Energy Transfer (FRET) was adopted for genotyping [18]. For developing two allele specific forward primers and one common reverse primer, 50 bp upstream and 50 bp downstream flanking sequences around the SNP were used (Additional file 1: Table S1). KASPar assays were carried out in $5 \mu \mathrm{L}$ reactions containing 10-20 ng of genomic DNA, $0.07 \mu \mathrm{L}$ of assay mix, $2.5 \mu \mathrm{L}$ of $1 \mathrm{x}$ KASP reaction mix and $0.43 \mu \mathrm{L}$ of distilled water. The PCR reaction was performed as follows: $15 \mathrm{~min}$ at $94{ }^{\circ} \mathrm{C}$; 10 touchdown cycles of $20 \mathrm{~s}$ at $94{ }^{\circ} \mathrm{C}$ and $60 \mathrm{~s}$ at 65 to $57^{\circ} \mathrm{C}$; and $26-35$ cycles of $20 \mathrm{~s}$ at $94{ }^{\circ} \mathrm{C}$ and $60 \mathrm{~s}$ at $57^{\circ} \mathrm{C}$. Fluorescence detection of the reaction was performed on an $\mathrm{ABI} 7900 \mathrm{HT}$ and the scatter plot of the allele call data was viewed using SNPViewer (http://www.lgcgenomics.com).

\section{Statistical analysis}

The Hardy-Weinberg equilibrium was tested for each of the SNPs based on the genotyping of ADPKD patients and healthy controls. Genotypic associations of SNPs between ADPKD and controls were tested using the CochranArmitage trend test. Pairwise linkage disequilibrium (LD) measures ( $D^{\prime}$ and $r^{2}$ ) and haplotype blocks were assessed under the default settings of the Haploview software [19]. Among the ADPKD patients, the Cochran-Armitage trend test was used to assess the potential associations between these polymorphisms and CKD stages. Further, multivariate logistic regression analysis was performed to adjust for the multiple risk factors. The Mantel-Haenszel $\chi^{2}$ test was performed to evaluate the influence of different genotypes on the relationship between different CKD stages and hypertension. All statistical analyses were performed using SPSS (version 16.0 for Windows, SPSS Inc, Chicago, IL).

\section{Results}

The mean age of the control group was $53.27 \pm 12.43$ years and the ADPKD group was $46.89 \pm 11.38$ years. All tagSNPs of the REN gene are polymorphic in both ADPKD and control groups and their distribution is documented in Table 1. Except for rs10900555, all tag-SNPs followed the Hardy-Weinberg Equilibrium in both control and ADPKD groups. The Cochran-Armitage trend test revealed that the 
Table 1 Genotype distribution of REN gene tag-SNPs between control and ADPKD patients

\begin{tabular}{|c|c|c|c|c|c|}
\hline Gene & Genotype & Control n (\%) & ADPKD n (\%) & OR (95 \% Cl) & $p$-Value (df-2) \\
\hline \multirow[t]{5}{*}{ rs2887284 } & CC & $70(66)$ & $58(56.8)$ & Reference & \\
\hline & CA & $33(31.1)$ & $38(37.2)$ & $1.39(0.78-2.49)$ & \\
\hline & AA & $3(2.83)$ & $6(5.8)$ & $2.41(0.58-10.08)$ & 0.301 \\
\hline & MAF & 18.4 & 24.5 & & \\
\hline & HWE-p & 0.703 & 0.945 & & \\
\hline \multirow[t]{5}{*}{ rs2368564 } & CC & 65 (61.3) & $54(52.9)$ & Reference & \\
\hline & TC & 38 (35.8) & $42(41.1)$ & $1.33(0.75-2.35)$ & \\
\hline & $\pi$ & $3(2.83)$ & $6(5.8)$ & $2.41(0.58-10.08)$ & 0.343 \\
\hline & MAF & 20.75 & 26.47 & & \\
\hline & HWE-p & 0.355 & 0.559 & & \\
\hline \multirow[t]{5}{*}{ rs1464816 } & GG & $58(54.7)$ & $56(54.9)$ & Reference & \\
\hline & TG & $40(37.7)$ & $41(40.2)$ & $1.06(0.60-1.88)$ & \\
\hline & $\pi$ & $8(7.5)$ & $5(4.9)$ & $0.65(0.20-2.10)$ & 0.718 \\
\hline & MAF & 26.4 & 25 & & \\
\hline & HWE-p & 0.762 & 0.467 & & \\
\hline \multirow[t]{5}{*}{ rs7521667 } & GG & $85(80.2)$ & $76(74.5)$ & Reference & \\
\hline & TG & 20 (18.8) & $26(25.5)$ & $1.45(0.75-2.81)$ & \\
\hline & $\pi$ & $1(0.94)$ & 0 & - & 0.430 \\
\hline & MAF & 10.38 & 12.75 & & \\
\hline & HWE-p & 0.882 & 0.14 & & \\
\hline \multirow[t]{5}{*}{ rs10900555 } & $\pi$ & $52(49.0)$ & $43(42.1)$ & Reference & \\
\hline & $\mathrm{TC}$ & 35 (33.0) & $46(45.1)$ & $1.59(0.88-2.89)$ & \\
\hline & CC & 19 (17.9) & $13(12.7)$ & $0.83(0.37-1.87)$ & 0.836 \\
\hline & MAF & 34.4 & 35.3 & & \\
\hline & HWE-p & 0.005 & 0.898 & & \\
\hline \multirow[t]{5}{*}{ rs6693954 } & $\pi$ & $56(52.8)$ & $48(47.0)$ & Reference & \\
\hline & TA & $46(43.4)$ & $46(45.1)$ & $1.17(0.67-2.05)$ & \\
\hline & AA & $4(3.7)$ & $8(7.8)$ & $2.33(0.66-8.23)$ & 0.283 \\
\hline & MAF & 25.47 & 30.3 & & \\
\hline & HWE-p & 0.14 & 0.505 & & \\
\hline \multirow[t]{5}{*}{ rs6676670 } & GG & $73(68.8)$ & 77 (75.5) & Reference & \\
\hline & $\mathrm{TG}$ & $28(26.4)$ & $22(21.6)$ & $0.75(0.39-1.42)$ & \\
\hline & $\pi$ & $5(4.7)$ & $3(2.94)$ & $0.57(0.13-2.47)$ & 0.171 \\
\hline & MAF & 17.9 & 13.7 & & \\
\hline & HWE-p & 0.292 & 0.367 & & \\
\hline \multirow[t]{5}{*}{ rs11571078 } & CC & $76(71.7)$ & 71 (69.6) & Reference & \\
\hline & TC & $28(26.4)$ & $28(27.4)$ & $1.07(0.58-1.98)$ & \\
\hline & $\pi$ & $2(1.89)$ & $3(2.94)$ & $1.61(0.26-9.89)$ & 0.659 \\
\hline & MAF & 15.09 & 16.67 & & \\
\hline & HWE-p & 0.753 & 0.905 & & \\
\hline
\end{tabular}

RR: Relative risk; Cl: confidence interval; MAF: minor allele frequency; HWp: Hardy-Weinberg $p$ value; * $p$-values for the Cochran-Armitage trend test

distribution of the REN genotypes was not significantly different between control and ADPKD groups (Table 1). Results of pair-wise linkage disequilibrium (LD) analysis with these 8 SNPs are shown in Fig. 1. We observed three small haplotype blocks; first composed of rs2887284 and rs2368564; second of rs7521667 and rs10900555 and third 


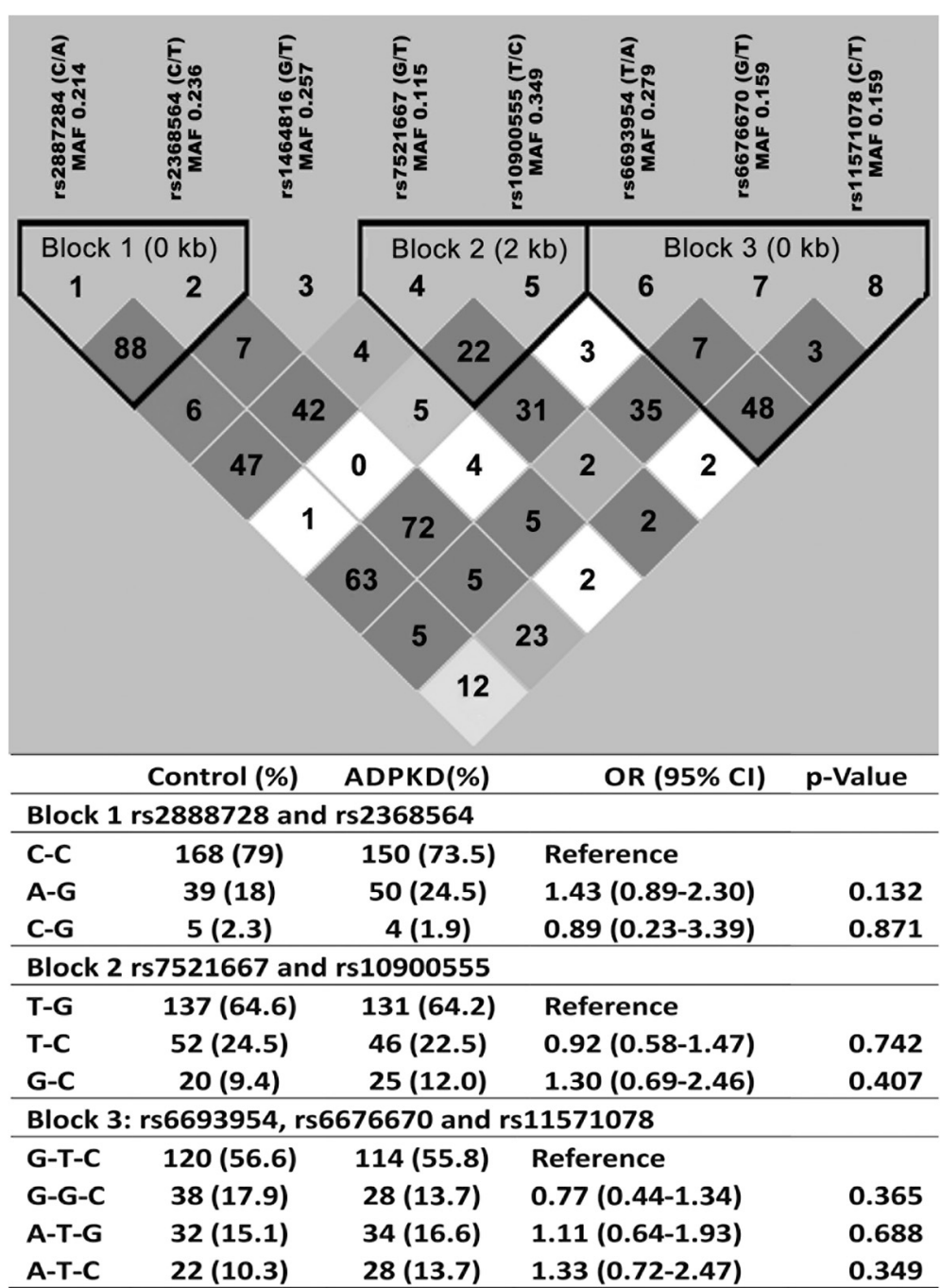

Fig. 1 Pairwise linkage disequilibrium between the tag-SNPS of the REN gene. Pairwise LD measures (D and $\left.r^{2}\right)$ were shown by the LD map. Square background color represents the D'/LOD and the values in cells are $r^{2}$ values (multiplied by 100). The REN gene haplotypes distribution in control and ADPKD patients was shown in the bottom

block of rs6693954, rs6676670 and rs11571078. However, the SNP rs1464816 remained outside the haplotype blocks. Haplotype frequencies from each haplotype block were not significantly different between ADPKD and control groups (Fig. 1).

Among ADPKD patients, $53 \%$ showed early CKD stage with $51.8 \pm 4.8$ years of age while $47 \%$ showed advanced CKD stage with a mean age of $35.8 \pm 6.6$. Univariate analysis showed that the distribution of REN tag-SNPs is not significantly different between early and advanced CKD groups (Table 2). None of the REN gene polymorphisms exhibited a confounding effect on the relationship between CKD progression and hypertension (Table 3). In multivariate analysis, the SNP rs1464816 showed significant association with increased CKD risk (TG vs. GG: $\mathrm{OR}=4.80$; $95 \% \mathrm{CI}=1.30-17.82 ; p=0.019$ ) (Table 4 ), when corrected for traditional risk factors viz. age, hypertension and family history of diabetes mellitus.

\section{Discussion}

Analysis of eight tag-SNPs within the REN gene did not show any significant association with ADPKD. Linkage disequilibrium analysis yielded three haplotype blocks and the haplotypes of the respective blocks are not statistically different between ADPKD and controls. However, the rs1464816 TG genotype showed a significant association with increased CKD risk in ADPKD in multivariate analysis. Earlier studies observed that the level of inactive renin found in normal plasma was significantly higher in uncomplicated diabetes mellitus and greatly increased in diabetic nephropathy [20, 21]. Further, the plasma of individuals with diabetic nephropathy showed increased levels 
Table 2 Effects of REN gene polymorphisms on CKD stages in ADPKD

\begin{tabular}{|c|c|c|c|c|}
\hline \multirow[t]{2}{*}{ Gene } & \multirow[t]{2}{*}{ Genotype } & \multicolumn{2}{|l|}{ CKD stages } & \multirow[t]{2}{*}{$p$-value* } \\
\hline & & Early stage $(n=53)$ & Advance stage $(n=49)$ & \\
\hline \multirow[t]{3}{*}{ rs2887284 } & $\mathrm{CC}$ & $30(56.6)$ & $28(57.1)$ & \\
\hline & CA & 18 (33.9) & $20(40.8)$ & \\
\hline & AA & $5(9.4)$ & $1(2.0)$ & 0.509 \\
\hline \multirow[t]{3}{*}{ rs2368564 } & $\mathrm{CC}$ & $28(52.8)$ & $26(53.0)$ & \\
\hline & TC & $20(37.7)$ & $22(44.9)$ & \\
\hline & $\pi$ & $5(9.4)$ & $1(2.0)$ & 0.525 \\
\hline \multirow[t]{3}{*}{ rs1464816 } & GG & $33(62.2)$ & $23(46.9)$ & \\
\hline & $\mathrm{TG}$ & $18(33.9)$ & $23(46.9)$ & \\
\hline & $\pi$ & $2(3.7)$ & $3(6.1)$ & 0.131 \\
\hline \multirow[t]{3}{*}{ rs7521667 } & GG & $41(77.3)$ & $35(71.4)$ & \\
\hline & TG & $12(22.6)$ & $14(28.5)$ & \\
\hline & $\pi$ & $0(0)$ & $0(0)$ & 0.492 \\
\hline \multirow[t]{3}{*}{ rs10900555 } & $\pi$ & $25(47.1)$ & $18(36.7)$ & \\
\hline & TC & $23(43.3)$ & $23(46.9)$ & \\
\hline & CC & $5(9.4)$ & $8(16.3)$ & 0.199 \\
\hline \multirow[t]{3}{*}{ rs6693954 } & $\pi$ & $25(47.1)$ & $23(46.9)$ & \\
\hline & TA & 21 (39.6) & $25(51.0)$ & \\
\hline & $\mathrm{AA}$ & $7(13.2)$ & $1(2.0)$ & 0.380 \\
\hline \multirow[t]{3}{*}{ rs6676670 } & GG & $43(81.1)$ & $34(69.3)$ & \\
\hline & $\mathrm{TG}$ & $10(18.8)$ & $12(24.4)$ & \\
\hline & $\pi$ & $0(0)$ & $3(6.1)$ & 0.076 \\
\hline \multirow[t]{3}{*}{ rs11571078 } & $\mathrm{CC}$ & $34(64.1)$ & $37(75.5)$ & \\
\hline & TC & $16(30.1)$ & $12(24.5)$ & \\
\hline & $\pi$ & $3(5.6)$ & $0(0)$ & 0.105 \\
\hline
\end{tabular}

HT: Hypertension; FH-DM: Family history of diabetes mellitus; OR: odds ratio; Cl: confidence interval. ${ }^{*}$ p-values for the Cochran-Armitage trend test

of acid activated renin [22]. Furthermore, mice treated with direct renin inhibitor showed adipocyte differentiation and improved insulin sensitivity [23]. Plasma renin levels were decreased in the elderly regardless of the presence or absence of an inverse relationship with blood pressure [24]. In healthy subjects, beginning at puberty mean plasma renin activity and its levels decline with wide variations in individual values, and reach their lowest levels during the sixth decade of life [25].

Studies using animal models have clearly demonstrated the involvement of the renin gene in the development of hypertension [26, 27]. The hypertensive patients with polycystic kidney disease showed significantly higher plasma renin activity than patients with only essential hypertension [28]. Several polymorphisms within the renin gene or its flanking sequences that were studied for hypertension yielded inconsistent results [29-33]. The rs2368564 of the REN gene failed to show a significant association with hypertension in a Japanese population [13]. In contrast to this, the rs6693954 polymorphism showed higher plasma renin activity levels and was found to be associated with hypertension in the HyperPath cohort of Caucasian subjects [34].

Using renin antiserum and an immunoperoxidase method in nephrectomy and autopsy specimens of adult polycystic kidneys, the distribution of renin-containing cells was identified in residual normal kidneys, scarred renal parenchyma and areas of fibrous tissue [35]. As the juxtaglomerular apparatus is the main source of renin, abnormal distribution of renin-containing cells were identified in the juxtaglomerular apparatuses (JGAs) of nephrectomy and autopsy specimens. Further, hyperplasia of these cells in JGAs of untreated autopsy cases was documented [35]. Furthermore, synthesis of renin by tubulocystic epithelia was confirmed by different techniques [36]. ADPKD cyst-derived cells in culture revealed that the renin is expressed primarily in cysts of distal tubule origin and in cyst-derived cells with distal tubule characteristics [10]. In addition, radiolabelling of renin and mRNA for renin has been detected in cyst wall epithelia and cyst fluids [37]. Higher levels of plasma renin activity are associated with greater rates of CKD in hypertensive 
Table 3 Association between CKD stages and hypertension stratified by REN genotypes

\begin{tabular}{|c|c|c|c|}
\hline Gene & Genotype & OR (95 \% Cl for HT) & $p$-Value* \\
\hline \multirow[t]{3}{*}{ rs2887284 } & CC & $3.0(0.29-30.69)$ & \\
\hline & $C A$ & $5.73(1.00-32.67)$ & \\
\hline & AA & $0.75(0.43-1.32)$ & 0.36 \\
\hline M-H Combined & & $3.42(0.97-12.07)$ & \\
\hline \multirow[t]{3}{*}{ rs2368564 } & $\mathrm{CC}$ & $1.92(0.16-22.56)$ & \\
\hline & $\mathrm{TC}$ & $6.67(1.21-36.74)$ & \\
\hline & $\pi$ & $0.75(0.43-1.32)$ & 0.286 \\
\hline M-H Combined & & $3.42(0.97-12.07)$ & \\
\hline \multirow[t]{3}{*}{ rs1464816 } & GG & $3.94(0.76-20.30)$ & \\
\hline & TG & $3.0(0.48-18.65)$ & \\
\hline & $\pi$ & & 0.828 \\
\hline M-H Combined & & $3.52(1.04-11.90)$ & \\
\hline \multirow[t]{3}{*}{ rs7521667 } & GG & $2.83(0.53-15.02)$ & \\
\hline & TG & $8.4(1.27-55.39)$ & \\
\hline & $\pi$ & $3.66(1.10-12.13)$ & 0.394 \\
\hline M-H Combined & & $4.47(1.28-15.58)$ & \\
\hline \multirow[t]{3}{*}{ rs10900555 } & $\pi$ & $1.09(0.16-7.31)$ & \\
\hline & $\mathrm{TC}$ & $11.73(1.33-103.79)$ & \\
\hline & $\mathrm{CC}$ & $4.67(0.30-73.38)$ & 0.227 \\
\hline M-H Combined & & $3.80(1.16-12.48)$ & \\
\hline \multirow[t]{3}{*}{ rs6693954 } & $\pi$ & $1.91(0.16-22.63)$ & \\
\hline & TA & $4.60(0.82-22.88)$ & \\
\hline & AA & $0.83(0.58-1.19)$ & 0.502 \\
\hline M-H Combined & & $2.84(0.77-10.51)$ & \\
\hline \multirow[t]{3}{*}{ rs6676670 } & GG & $3.55(0.90-13.96)$ & \\
\hline & TG & $2.75(0.21-35.84)$ & \\
\hline & $\pi$ & & 0.863 \\
\hline M-H Combined & & $3.37(1.01-11.26)$ & \\
\hline \multirow[t]{3}{*}{ rs11571078 } & CC & $3.75(0.70-20.03)$ & \\
\hline & $\mathrm{TC}$ & $2.27(0.36-14.45)$ & \\
\hline & $\pi$ & & 0.594 \\
\hline M-H Combined & & $3.01(0.88-10.37)$ & \\
\hline
\end{tabular}

HT: Hypertension; M-H: Mantel-Haenszel

*Homogeneity test $p$ value

patients of an ethnically diverse population in southern California [38]. However, no study has been conducted to ensure the association of these polymorphisms with hypertension in ADPKD.

\section{Conclusion}

In summary, our case-control study provides evidence that the polymorphism rs1464816 in REN gene is associated with CKD progression in ADPKD. The potential of the present study is limited, as we have not analyzed variations in PKD1 and PKD2 for ADPKD subjects although
Table 4 Adjusted effects of risk factors on CKD stages

\begin{tabular}{lll}
\hline Factors & OR $(95 \% \text { Cl })^{\mathrm{a}}$ & $p$ value $^{*}$ \\
\hline HT: Yes vs No & $6.63(1.38,31.81)$ & 0.018 \\
SEX: M vs F & $0.45(0.16,1.24)$ & 0.123 \\
Age: $(40,60$ year) vs, $\leq 40$ year & $6.71(1.99,22.62)$ & 0.002 \\
Age: $(60,90$ year) vs, $\leq 40$ year & $15.3(2.44,96.06)$ & 0.004 \\
FH-DM: Yes vs No & $7.67(2.54,23.14)$ & 0.001 \\
rs2887284:CA vs CC & $2.41(0.12-47.68)$ & 0.563 \\
rs2887284:AA vs CC & - & - \\
rs2368564: TC vs CC & $0.68(0.00-62.02)$ & 0.87 \\
rs2368564: TT vs CC & - & - \\
rs1464816: TG vs GG & $4.80(1.30-17.82)$ & 0.019 \\
rs1464816: TT vs GG & $3.52(0.25-48.93)$ & 0.347 \\
rs7521667: TG vs GG & $5.00(0.02-1004.64)$ & 0.551 \\
rs7521667: TT vs GG & - & - \\
rs10900555: TC vs TT & $0.52(0.73-3.80)$ & 0.525 \\
rs10900555: CC vs TT & $0.13(0.00-9.21)$ & 0.352 \\
rs6693954: TA vs TT & $2.58(0.62-106.83)$ & 0.618 \\
rs6693954: AA vs TT & - & - \\
rs6676670: TG vs GG & $2.87(0.38-21.60)$ & 0.305 \\
rs6676670: TT vs GG & - & - \\
rs11571078: TC vs CC & $0.60(0.00-51.79)$ & 0.822 \\
rs11571078: TT vs CC & - & - \\
\hline
\end{tabular}

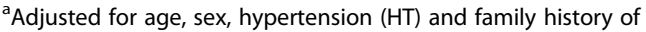
diabetes (FH-DM)

OR: odds ratio; $\mathrm{Cl}$ : confidence interval; **Wald test $p$ value

they were recruited based on clinical criteria. Therefore, further functional validation of these observational findings needs to be conducted. In addition, the nested study strategy adopted in this study may introduce selection bias and the small sample size used in this study is another limiting factor of statistical power. Lastly, the plasma renin activity levels were not determined and correlated with the progression of CKD as well as REN variants.

\section{Additional file}

\section{Additional file 1: Table S1. Primers used for genotyping REN tag-SNPS.} (DOCX $13 \mathrm{~kb})$

\section{Competing interests}

The authors declare that they have no competing interests

\section{Authors' contributions}

BLVKS and PS defined the research theme and designed methods. GR has carried out the molecular genetic studies. BLVKS, GR and RE analyzed the data, interpreted the results and wrote the paper. All authors read and approved the final manuscript.

\section{Acknowledgement}

This work was supported by the GATE project for young investigator of Sri Ramachandra University. 


\section{Author details}

'Department of Biomedical Sciences, Sri Ramachandra University, Chennai, India. ${ }^{2}$ Department of Nephrology, Sri Ramachandra University, Chennai, India. ${ }^{3}$ Genetic Lab, Department of Biochemistry, Sickle Cell Institute Chhattisgarh, Pt. JNM Medical College, Raipur 492001CG, India.

Received: 27 April 2015 Accepted: 28 December 2015

Published online: 11 January 2016

\section{References}

1. Torres VE, Harris PC. Autosomal dominant polycystic kidney disease: the last 3 years. Kidney Int. 2009;76:149-68.

2. Norman J. Fibrosis and progression of autosomal dominant polycystic kidney disease (ADPKD). Biochim Biophys Acta. 1812;2011:1327-36.

3. Hateboer N, v Dijk MA, Bogdanova N, Coto E, Saggar-Malik AK, San Millan $J$, et al. Comparison of phenotypes of polycystic kidney disease types 1 and 2. European PKD1-PKD2 Study Group. Lancet. 1999;353:103-7.

4. Magistroni R, He N, Wang K, Andrew R, Johnson A, Gabow P, et al. Genotype-renal function correlation in type 2 autosomal dominant polycystic kidney disease. J Am Soc Nephrol. 2003;14:1164-74.

5. Rossetti S, Burton S, Strmecki L, Pond GR, San Millan JL, Zerres K, et al. The position of the polycystic kidney disease 1 (PKD1) gene mutation correlates with the severity of renal disease. J Am Soc Nephrol. 2002;13:1230-7.

6. Schrier RW, McFann KK, Johnson AM. Epidemiological study of kidney survival in autosomal dominant polycystic kidney disease. Kidney Int. 2003;63:678-85.

7. Thurman JM, Schrier RW. Comparative effects of angiotensin-converting enzyme inhibitors and angiotensin receptor blockers on blood pressure and the kidney. Am J Med. 2003;114:588-98.

8. Doulton TW, Saggar-Malik AK, He FJ, Carney C, Markandu ND, Sagnella GA, et al. The effect of sodium and angiotensin-converting enzyme inhibition on the classic circulating renin-angiotensin system in autosomal-dominant polycystic kidney disease patients. J Hypertens. 2006;24:939-45.

9. Harrap SB, Davies DL, Macnicol AM, Dominiczak AF, Fraser R, Wright AF, et al. Renal, cardiovascular and hormonal characteristics of young adults with autosomal dominant polycystic kidney disease. Kidney Int. 1991:40:501-8.

10. Loghman-Adham M, Soto CE, Inagami T, Cassis L. The intrarenal reninangiotensin system in autosomal dominant polycystic kidney disease. Am J Physiol Renal Physiol. 2004;287:F775-88.

11. Kocyigit I, Yilmaz MI, Unal A, Ozturk F, Eroglu E, Yazici C, et al. A link between the intrarenal renin angiotensin system and hypertension in autosomal dominant polycystic kidney disease. Am J Nephrol. 2013;38:218-25.

12. Kim UK, Jin DK, Ahn C, Shin JH, Lee KB, Kim SH, et al. Novel mutations of the PKD1 gene in Korean patients with autosomal dominant polycystic kidney disease. Mutat Res. 2000:432:39-45.

13. Chang JM, Hwang SJ, Kuo HT, Tsai JC, Guh JY, Chen HC, et al. Fatal outcome after ingestion of star fruit (Averrhoa carambola) in uremic patients. Am J Kidney Dis. 2000;35:189-93.

14. Hwang IS, Tang F. Peripheral distribution and gene expression of adrenomedullin in the rat: possible source of blood adrenomedullin. Neuropeptides. 2000;34:32-7.

15. Ravine D, Gibson RN, Walker RG, Sheffield LJ, Kincaid-Smith P, Danks DM. Evaluation of ultrasonographic diagnostic criteria for autosomal dominant polycystic kidney disease 1. Lancet. 1994;343:824-7.

16. NKF. KDOQI clinical practice guidelines for chronic kidney disease: evaluation, classification, and stratification. Am J Kidney Dis. 2002;39:S1-S266.

17. Sambrook J, Russell DW. Molecular cloning : a laboratory manual. 3rd ed. Cold Spring Harbor, N.Y.: Cold Spring Harbor Laboratory Press; 2001.

18. Didenko W. DNA probes using fluorescence resonance energy transfer (FRET): designs and applications. Biotechniques. 2001;31:1106-16. 1118, 1120-110.

19. Barrett JC, Fry B, Maller J, Daly MJ. Haploview: analysis and visualization of LD and haplotype maps. Bioinformatics. 2005:21:263-5.

20. Bryer-Ash M, Ammon RA, Luetscher JA. Increased inactive renin in diabetes mellitus without evidence of nephropathy. J Clin Endocrinol Metab. 1983:56: 557-61.

21. Fujii $\mathrm{S}$, Shimojo $\mathrm{N}$, Wada $\mathrm{M}$, Funae $\mathrm{Y}$. Plasma active and inactive renin in patients with diabetes mellitus. Endocrinologia japonica. 1980;27:65-8.

22. Peti-Peterdi J, Kang JJ, Toma I. Activation of the renal renin-angiotensin system in diabetes-new concepts. Nephrol Dial Transplant. 2008;23:3047-9.

23. Iwai $M$, Kanno H, Tomono $Y$, Inaba S, Senba I, Furuno $M$, et al. Direct renin inhibition improved insulin resistance and adipose tissue dysfunction in type 2 diabetic KK-A(y) mice. J Hypertens. 2010;28:1471-81.
24. Weidmann P, De Myttenaere-Bursztein S, Maxwell MH, de Lima J. Effect on aging on plasma renin and aldosterone in normal man. Kidney Int. 1975;8: 325-33.

25. Bauer $\mathrm{JH}$. Age-related changes in the renin-aldosterone system. Physiological effects and clinical implications. Drugs Aging. 1993;3:238-45.

26. Dene H, Wang SM, Rapp JP. Restriction fragment length polymorphisms for the renin gene in Dahl rats. J Hypertens. 1989;7:121-6.

27. Bohlender J, Fukamizu A, Lippoldt A, Nomura T, Dietz R, Menard J, et al. High human renin hypertension in transgenic rats. Hypertension. 1997;29:428-34.

28. Chapman AB, Johnson A, Gabow PA, Schrier RW. The renin-angiotensinaldosterone system and autosomal dominant polycystic kidney disease. N Engl J Med. 1990;323:1091-6.

29. Qi Y, Niu W, Cen W, Cui C, Zhuoma C, Zhuang L, et al. Strong association of the renin Taql polymorphism with essential hypertension in Chinese Han and Tibetan populations. J Hum Hypertens. 2007;21:907-10.

30. Zhu X, Chang YP, Yan D, Weder A, Cooper R, Luke A, et al. Associations between hypertension and genes in the renin-angiotensin system. Hypertension. 2003;41:1027-34

31. Niu W, Qi Y, Guo S, Gao P, Zhu D. Association of renin Bgll polymphism with essential hypertension: a meta-analysis involving 1811 cases and 1626 controls. Clin Exp Hypertens. 2010;32:431-8.

32. Matsubara M. Genetic determination of human essential hypertension. Tohoku J Exp Med. 2000;192:19-33.

33. Frossard PM, Lestringant GG, Malloy MJ, Kane JP. Human renin gene Bgll dimorphism associated with hypertension in two independent populations. Clin Genet. 1999:56:428-33.

34. Kim YK, Hwang MY, Woo JS, Jung JS, Lee SH. Effect of arachidonic acid metabolic inhibitors on hypoxia/reoxygenation-induced renal cell injury. Ren Fail. 2000;22:143-57.

35. Graham PC, Lindop GB. The anatomy of the renin-secreting cell in adult polycystic kidney disease. Kidney Int. 1988;33:1084-90.

36. Torres VE, Donovan KA, Scicli G, Holley KE, Thibodeau SN, Carretero OA, et al. Synthesis of renin by tubulocystic epithelium in autosomal-dominant polycystic kidney disease. Kidney Int. 1992;42:364-73.

37. Zeier M, Ritz E, Geberth S, Gonzalo A. Genesis and significance of hypertension in autosomal dominant polycystic kidney disease. Nephron. 1994;68:155-8.

38. Hwang SS, Park YH, Lee CB, Jung YJ. Spontaneous rupture of hydronephrotic kidney during pregnancy: value of serial sonography. J Clin Ultrasound. 2000:28:358-60.

\section{Submit your next manuscript to BioMed Central and we will help you at every step:}

- We accept pre-submission inquiries

- Our selector tool helps you to find the most relevant journal

- We provide round the clock customer support

- Convenient online submission

- Thorough peer review

- Inclusion in PubMed and all major indexing services

- Maximum visibility for your research

Submit your manuscript at www.biomedcentral.com/submit
) Biomed Central 